\title{
Inflexiones de la realidad. Debates alrededor de la novela, el "compromiso" y el realismo en los años sesenta
}

\section{Marcos Zangrandi}

Universidad de Buenos Aires, Facultad de Filosofía y Letras, Instituto de Literatura Hispanoamericana / CONICET, Argentina

\begin{abstract}
Resumen
Este artículo analiza los debates acerca del realismo en la literatura argentina a partir de dos ensayos clave: Seis novelistas de la nueva promoción (1959) de Noé Jitrik y Realismo y realidad en la narrativa argentina (1961) de Juan Carlos Portantiero. A partir de ellos, se estudian los conceptos de "realismo" y de "realidad" que se convirtieron en bastiones de disputa en las transformaciones del campo cultural durante el cambio de décadas. De este modo, mientras que el texto de Portantiero, desde la tradición marxista, embiste contra la literatura del "compromiso" y señala, en cambio, la tradición de la literatura argentina de izquierda, Jitrik pone de manifiesto zonas de lo ambiguo y de lo liminar a partir de las cuales se pueden pensar otras dimensiones de la realidad en la literatura de aquel tiempo.
\end{abstract}

PALABRAS CLAVE: Realismo, literatura argentina, siglo XX, jitrik, Portantiero

Inflections of reality. Debates around the novel, "commitment" and realism in the sixties

\begin{abstract}
This article analyzes the debates about realism in Argentine literature from two essays: Six novelists of the new promotion (1959) of Noé Jitrik and Realism and reality in the Argentine narrative (1961) by Juan Carlos Portantiero. From them, the concepts of "realism" and "reality" are studied; both became points of dispute of the cultural field during the change of decades. In this way, while Portantiero's text, from the Marxist tradition, attacks literature of "commitment", and points out, instead, the tradition of left-wing Argentine literature, Jitrik reveals areas of ambiguity and borders from which other dimensions of reality could be thought into the literature of that years.
\end{abstract}




\section{Inflexões da realidade. Debates em torno do romance, "compromisso" e realismo nos anos 60}

\section{Resumo}

Este artigo analisa os debates sobre o realismo na literatura argentina a partir de dois ensaios-chave: Seis romancistas da nova promoção (1959) de Noé Jitrik e Realismo e realidade na narrativa argentina (1961) de Juan Carlos Portantiero. A partir deles, estudam-se os conceitos de "realismo" e "realidade", que se tornaram bastiões de disputa nas transformações do campo cultural durante o câmbio de décadas. Desta forma, enquanto o texto de Portantiero, da tradição marxista, ataca a literatura do "compromisso" e aponta, em vez disso, a tradição da literatura argentina de esquerda, Jitrik revela áreas de ambiguidade e margens do qual poder pensar outras dimensões da realidade na literatura da aquela época.

PALAVRAS- CHAVE: Realismo, literatura argentina, século XX, Jitrik, Portantiero

Nada más frecuente para un investigador de la cultura argentina de los cincuenta y los sesenta que encontrarse una y otra vez con los términos "realismo", "realidad" y con otras palabras asociadas. Hay dos rasgos notables en esta recurrencia. Por un lado, una utilización que excede el ámbito estricto de la tradición marxista en el que el realismo tuvo una importante teorización (aunque este espacio seguiría siendo uno de los pivotes fundamentales del debate). Por otro, la construcción discursiva de la "realidad" como medida necesaria y como una presencia obligada. Esto es, no solo como modo de poner en relación la literatura y la sociedad o de señalar una corriente, sino como una urgencia que orbita la producción y la lectura.

Es conocido el lugar que tuvo el concepto de "realidad" en los núcleos de la renovación crítica durante los años cincuenta: Centro, Contorno, Ciudad, y otras. La extensión de esa "realidad" abarcaba, entre otros aspectos, las objeciones a la idea de literatura como artificio, el rechazo al cosmopolitismo, el retorno del "cross a la mandíbula" arltiano y la inscripción de la discusión política al interior de la literatura. ${ }^{1}$ Empujados por la potencia de estas formulaciones y por los acontecimientos políticos de los años peronistas, otros espacios y otras voces no emergentes - muchos de ellos alejados de toda perspectiva renovadora- atacaron o adhirieron, pero nunca pudieron ser impasibles frente a un espectro de la "realidad" que se convertía en criterio dominante de la literatura y de la crítica de la época.

El modo en que este concepto atraviesa las discusiones culturales de estas décadas y se transforma en el objeto de disputa excede las intenciones de este trabajo. Voy a limitarme, por esto, a dos ensayos que entiendo claves para comprender los alcances del debate. Me refiero a Seis novelistas de la nueva promoción, de Noé Jitrik (1959) y a Realismo y realidad en la narrativa argentina (1961), de Juan Carlos Portantiero. Aunque desde puntos de vista disímiles (pero no necesariamente opuestos), ambos textos

\footnotetext{
1 Me refiero al número 2 de Contorno (mayo de 1954), dedicado a Roberto Arlt; esta intervención crítica fue central para integrar a este autor en el canon de la literatura argentina. A ello es necesario sumar las lecturas de Arlt por parte de Oscar Masotta, reunidas en Sexo y traición en Roberto Arlt (1965). En la película El jefe (1958, dir. Fernando Ayala), con guion de David Viñas, hay un guiño a la expresión de Arlt: Berger, imagen alegórica de Perón, señala que su nombre, de resonancias sajonas, es como "un cross a la mandíbula". En mi libro Familias póstumas (2016) analicé el criterio de la "realidad" (evidentemente cruzado por una pauta de género) en la lectura de la novela Los ídolos de Manuel Mujica Lainez.
} 
advierten la dimensión y centralidad de la "realidad" en la narrativa argentina de estos años; ambos, a la vez, buscan intervenir en las polémicas político-culturales alrededor del concepto de "realidad" que estaban impactando en el campo de la literatura.

Los dos libros, tan próximos en el tiempo, aparecieron en un momento de inflexión de los escenarios políticos argentino y latinoamericano. Mientras el frondicismo recorría su derrotero de síntesis modernizadora y autoritarismo liberal, la revolución cubana comenzaba a repercutir en todo el continente y alentaba el avance de las izquierdas. En el país, tras el fracaso de los proyectos de Frondizi, el peronismo, aun proscrito, seguía repercutiendo en la vida social argentina, ya como propedéutica fallida de la revolución -tal era la lectura de Sebreli en el número de Contorno dedicado al peronismo-, ya como irrupción traumática, ya como revelador de realidades, ya como promesa emancipadora. Las tensiones de esta trama atraviesan los argumentos de Jitrik y de Portantiero sobre el territorio progresivamente politizado de la cultura.

\section{Jitrik: la nueva novela en constelación de la "realidad"}

La nueva promoción estudia un grupo de novelistas argentinos "jóvenes", cuya producción, que reconoce de calidad e innovación, se inicia relativamente a principio de la década de 1950. Jitrik no busca inscribir esas figuras y libros en la herencia realista y naturalista local; tampoco está interesado en constituir una tradición a la que ellos responden. No hay una incursión teórica manifiesta -salvo una breve referencia a Blanchot-, ni una conceptualización sistemática de, por ejemplo, todo lo que implica referirse al realismo en el ámbito de la teoría literaria. En cambio, realiza un trazado panorámico, contemporáneo y ciertamente optimista sobre escritores y textos reunidos por determinadas "conexiones", por el trabajo sobre la forma novelística y por el lazo de la "promoción" (un término flexible que soslaya la idea de generación y que propone vínculos contingentes).

El enlace escritor/sociedad de esta "nueva promoción" está atravesado necesariamente por la "realidad". Para Jitrik, los narradores de "la nueva promoción" poseerían en común una "representatividad temporal", una "encarnación" de la época, una "penetración" del tiempo (1959: 20). Lejos de un vínculo abstracto, retórico o metafísico con el mundo, novelas y novelistas se afirmarían sobre un presente asumido como propio, sobre la experiencia crítica y sobre una postura definida. De este modo, el vértice "realidad" redefine la conexión entre autor y obra, afecta de manera crucial la posición del escritor y dimensiona la producción y la significación social de la novela.

De acuerdo con esto, la reciprocidad obra/ autor/ realidad se manifiesta a través de tres "conexiones". La primera de ellas reconoce la incorporación a las ficciones de lugares, objetos y temas contemporáneos. Efectivamente, varias de las novelas de esta época escenifican pasajes de la vida política argentina de los últimos años, por ejemplo de los gobiernos de Yrigoyen (La casa del ángel de Beatriz Guido, Los dueños de la tierra de David Viñas), de la década de los gobiernos conservadores (Fin de fiesta de Beatriz Guido) y del peronismo (Las leyes de la noche de Héctor A. Murena, Los años despiadados de Viñas). Estos textos desplazan la literatura de una zona cosmopolita y la posicionan en un espacio situado y polémico, atravesado por el debate político y por las problemáticas propias de aquel presente. A esto se le suma la insistencia de algunos escritores, en particular de David Viñas, por extremar el acercamiento del lenguaje al mundo y de referencias hacia detalles cotidianos. Son, todos ellos, procedimientos que actualizaban aspectos constitutivos del realismo, esto es, la incorporación de episodios recientes y de rasgos corrientes a la literatura (Gramuglio, 2014).

La segunda conexión con la realidad que destaca Noé Jitrik es el aditamento de procedimientos de algunos territorios discursivos por entonces novedosos para la 
literatura. La confluencia con las técnicas y enfoques periodísticos otorgaba a la literatura rapidez sintáctica, austeridad verbal y la incorporación de criterios de objetividad. El tratamiento sistemático del pasado para dar cuenta de los fenómenos del presente eran los aportes del psicoanálisis a la novela. Finalmente, las descripciones a la manera de una panorámica cinematográfica o el montaje de cuadros narrativos acercaban la narrativa a los recursos propios de la pantalla grande. ${ }^{2}$ Es oportuno advertir, asimismo, que varios escritores que estudia Jitrik estaban particularmente interesados en el cine o, más aún, escribían para la pantalla grande; ejemplos claros de esto eran, hacia 1959, las duplas de trabajo entre Beatriz Guido y Torre Nilsson (Dias de odio, 1953; La casa del ángel, 1956; La caída, 1958; El secuestrador, 1958; Fin de fiesta, 1960, entre otras) y de David Viñas con Fernando Ayala (El jefe, 1958; El candidato, 1959) e incluso de Juan José Manauta con Enrique Dawi (Río abajo, 1959). Acaso lo más novedoso de la relación de la "nueva promoción" con el cine se encontraba menos en los procedimientos novelísticos que en la confluencia múltiple y en el atractivo creciente por parte de la literatura respecto de un territorio inscripto en la cultura de masas.

La "actitud novelística", la última "conexión" entre literatura y realidad, rodea específicamente la relación entre el escritor y el mundo. Tal posición implica la renuncia a la neutralidad de la voz narrativa, y, en cambio, la toma de posición del novelista, ya convertido en militante frente a los acontecimientos y los procesos de su tiempo. A partir de este giro, además, se quería

la invitación o la presión sobre el lector para que del libro surja la actitud que lo haga evadirse del límite de la receptividad subjetiva, recóndita y satisfactoria para convertirlo en un objeto de uso, discutible y aceptable, apasionado y partícipe de las cosas que nos llevan y nos mueven en la vida diaria. (1959: 26)

En este sentido, el escritor y la novela, el libro y el lector, lejos de una postura contemplativa o elusiva, se encuentran frente a una "realidad", esta vez comprendida como una instancia que estaría velada (por el lenguaje, por la ideología) y a la que urge poner de manifiesto a partir de una torcedura (la "toma de postura") que rompería una falsa imparcialidad. Lo que es fundamental aquí es la formulación de la literatura (en todas sus dimensiones: sus agentes, su lenguaje, sus circuitos) como instrumento revelador y, en esta labor, arrinconada frente a un objeto, la "realidad", de un modo necesario; esto es, de cara a la cual hay que responder ineludiblemente.

Se trata de una pauta vinculada con las formulaciones de Jean- Paul Sartre en ¿Qué es la literatura? -la editorial Losada lo había traducido y publicado en 1950 en Buenos Aires-. En este ensayo, el pensador francés rechaza la postura imparcial del escritor para dar lugar, en cambio, al compromiso inexcusable con su realidad, a la condición necesariamente situada de la literatura y a la responsabilidad consecuente con estas premisas. Al respecto, señalaba: "el escritor no tiene modo alguno de evadirse, queremos que se abrace estrechamente con su época; es su única oportunidad; su época está hecha para él y él está hecho para ella" (2003: 12). Pueden advertirse en esta cita los modos reiterativos en que Sartre subraya la condición forzosa entre el escritor y su presente. A la par (y aquí obsérvese el paralelo con el texto de Jitrik), al asumir una postura, la literatura se convierte en una mecánica desentrañadora de un mundo cubierto por un velo ideológico; un

2 A las observaciones de Jitrik, hay que agregar que la descripción pictórica fue un procedimiento propio de la modernidad literaria del siglo XIX. György Lukács (1966) en sus artículos sobre el realismo había fustigado las descripciones a la manera de una naturaleza muerta en Flaubert y en Zolá, en tanto deshumanizarían la relación de la literatura con la realidad (este último concepto, entiéndase, en un sentido marxista). 
aguijón a las conciencias de los lectores a la espera de que éstos "asuman todas sus responsabilidades" (Sartre, 2003: 70) ${ }^{3}$.

Los caracteres de este lazo entre literatura y realidad que señala Jitrik se fortalecieron en los siguientes años. Solo como un ejemplo de esta concepción dominante, en 1965 la revista Confirmado publicó una entrevista a Manuel Mujica Lainez en ocasión de la aparición de su novela El unicornio (1965). Desde los años cincuenta, Mujica había sido el blanco predilecto de las revistas en las que se nucleaban nuevos enfoques literarios y culturales. ${ }^{4}$ El unicornio, con su preferencia por un mundo fantástico y su embelesamiento medievalista, era el objetivo perfecto para las perspectivas realistas de los sesenta (las que, por otra parte, perdían de vista las figuras transgénero y el lenguaje camp avant la lettre). Lo interesante de la entrevista de Confirmado no son las respuestas del narrador, sino las preguntas que le realiza el cronista (que no está identificado). Reproduzco algunas de ellas:

¿No cree que el lenguaje que utiliza en El unicornio, recargado de palabras de añejo prestigio poético (peristilos, sahumerios, capiteles, silfos, querubes, laúdes, guedejas y cálices) resulta ajeno al lector argentino de 1965? [...]. ¿Esas minuciosas reconstrucciones históricas no lo marginan de la literatura argentina y de su problemática actual? [...]. El unicornio está narrada en primera persona por un hada. También aparecen duendes, ángeles, elfos, unicornios y centauros. Más allá de la creación literaria, ¿esos seres, el ocultismo, la magia, tienen vigencia para usted? (1965:42-43).

El desdén de Mujica Lainez hacia estos reclamos se resume en la respuesta final: "Para escribir Bomarzo y El unicornio, o mi próxima novela, El inca, es necesario documentarse leyendo increíbles cantidades de historia, lo que no deja tiempo para enterarse de la literatura sociologizante y otros pasajeros dernier cri" (1965: 43). En los cuestionamientos de Confirmado es evidente la idea de una literatura y de un lenguaje que deben, a modo de exigencia, hacer manifiesta una "realidad" y que impugnan al mismo tiempo otras posibilidades. Las palabras irónicas de Mujica Lainez, por su lado, marcan que tal criterio era una construcción reciente y, más aún, considerado en tales condiciones, no era más que una premisa frívola.

Aun así, esta toma de una postura es una de las perspectivas en que "realidad" adquiere presencia dominante dentro de la nueva novela argentina. Para Jitrik, la "realidad" es conciencia del mundo, pero también es la referencia a episodios recientes, concretos y cotidianos. Son los procedimientos novedosos que diversifican el acercamiento al mundo. La nueva promoción trabaja sobre la multiplicidad convergente con que la literatura argentina de su tiempo rodea el ideario de la "realidad". Un concepto que, aunque sujeto a una teoría y a una tradición, aparece con un atractivo novedoso, vinculado específicamente con los procesos y con las expectativas de esta coyuntura y que requiere ser pensado bajo nuevos parámetros.

En el análisis de cada uno de los seis novelistas de la "nueva promoción" (Guido, Murena, Viñas, Rodríguez, Manauta, Di Benedetto), Jitrik pone en claro este criterio diversificado y a la vez convocante de la "realidad". Las leyes de la noche (1958) y La fatalidad de los cuerpos (1955) de Héctor A. Murena, pese a su fondo transcendental,

3 Noé Jitrik me señaló en una conversación personal reciente que leía más las obras literarias (La náusea, El muro, Las moscas, A puerta cerrada, y otras) que los ensayos filosóficos y críticos de Jean Paul Sartre. Aun así, las muchas de las ideas de Sartre, transformadas en convicciones, circulaban de modo "ambiental” entre los jóvenes intelectuales de la década de 1950.

4 En Familias póstumas (2016) apunto en detalle las numerosas lecturas de todo el arco de la crítica hacia la novela Los ídolos (1953) de Manuel Mujica Lainez. Entre ellas, son interesantes los ataques de las revistas de la izquierda cultural (Contorno y Centro principalmente) en las que se impugnaba la literatura de Mujica Lainez como evasiva y artificiosa. Sobre las transformaciones en el campo de la cultura, ver los textos de Terán (1991) y de Cernadas (1997). 
exploran situaciones individuales crudas que fluctúan entre la rutina, la angustia y el destino trágico. Los mejores logros de Alberto Rodríguez (h.) y de Juan José Manauta (Matar la tierra, 1952, y Las tierras blancas, 1956, respectivamente) incorporan problemáticas sociales y políticas a partir de procedimientos innovadores. La narrativa de Beatriz Guido se acerca a la realidad cuando se aleja de los laberintos psicológicos de las primeras novelas ( La casa del ángel, 1955, y La caída, 1957) y "reacciona vigorosamente" en Fin de fiesta (1960), la novela en la que, además de ensayar una forma novedosa, añade elementos cotidianos y concretos (en particular las oscuras vivencias sexuales de los personajes) y refiere episodios de la vida política argentina (el caudillismo conservador de los treinta y el inicio del peronismo). Un rumbo paralelo encuentra Jitrik en los textos de Viñas. El énfasis en aspectos sensoriales y conflictos domésticos de las primeras novelas (Cayó sobre su rostro, 1955; Los años despiadados, 1956; Un dios cotidiano, 1957) encuentran en Los dueños de la tierra (1958) la conexión precisa entre la literatura y la sociedad. Aquí, a partir de la narración de los conflictos obreros de la Patagonia durante los años veinte, Viñas construye una visión completa y compleja de un problemática social y política encarnada en las acciones de los personajes.

La inclusión de Antonio Di Benedetto en la "nueva promoción" es, acaso, la maniobra crítica más importante de Jitrik. Difícilmente los libros de Di Benedetto (Mundo animal, 1953; El pentágono, 1955; Zama, 1956), en los que explora territorios de lo extraño y de lo onírico, podían ser comprendidos con parámetros de la "realidad", por lo menos no en el mismo sentido que funciona para los otros cinco narradores. Antes de una progresión que desembocaría en un encuentro con el mundo (como sucedería con Guido y Viñas), Zama operaría en "zonas límites de la realidad, allí donde puede desaparecer la consistencia de las cosas borrada por el sueño. [Di Benedetto] emplea elementos novelísticos de hermosa solución como la gran casa, con dos alas y dos entradas, las mujeres veladas, de cuya realidad no se puede hacer afirmaciones pero cuya presencia tampoco puede negarse" (1959: 54-55). Es particularmente interesante integrar esta reflexión en un debate sobre un nuevo realismo, porque Jitrik está pensando no desde la mímesis o desde la captación de la complejidad social, sino desde una zona divergente a esas variantes. El crítico observa, así, que había una parte de la narrativa que, rodeando el concepto de "realidad", se escapaba de las acepciones dominantes del realismo, esto es, de aquellas que descansan sobre la fidelidad entre el mundo y el lenguaje y sobre la confianza entre signo y referente (Gramuglio, 2014).

La referencia a Maurice Blanchot es fundamental para comprender este punto. En efecto, para el crítico francés la literatura no puede dar cuenta del mundo, ni pretender una representación de la realidad. El lenguaje literario prefiere lo incierto y lo inquieto, soslaya las esencias, se afirma y se deshace sobre zonas de sentido inestables e indefinidas. La literatura, advierte Blanchot, recorre una y otra vez un gesto órfico: busca continuamente las cosas que han sido borradas, retorna continuamente a ellas insistiendo en un inevitable vacío. Nada de transparencia entre signo y referente, entonces, sino un movimiento pendular sobre lo inhallable. En este sentido, a diferencia del lenguaje corriente, que quiere limitar el malentendido y la dispersión, la literatura se alimenta de la ambigüedad del sentido, de la multiplicidad de valores, del derrame inevitable que se desprende de la palabra literaria (Blanchot, 1981). En contigüidad con esto, Jitrik apunta que la literatura "sólo puede aspirar a alcanzar lo inaccesible, el más allá de toda experiencia humana, lo cual significa un hundimiento en la ambigüedad" (1959: 45). De este modo, pone de manifiesto que hay una narrativa que no puede ser pensada ni desde el concepto de mímesis, ni desde una aprehensión, ni siquiera desde un posicionamiento del escritor, y aun así, considerarla anexa a la "realidad". Aquí, parece decir Jitrik, hay una narrativa que reclama nuevos criterios para pensar la extensión de la "realidad". 
En 1960 Noé Jitrik publicó el artículo "Un precursor argentino del nuevo realismo" en el semanario uruguayo Marcha, que puede considerarse como un complemento de las preguntas y los recorridos que había abierto en La nueva promoción. En este texto, el crítico advertía una nueva corriente forjada por jóvenes escritores franceses (Robbe- Grillet, Butor, Sarraulte, Lagrolet) que, si bien encontraba referentes en la narrativa moderna, estaba forjando un nuevo modo de realismo. En este caso, ese nouveau realisme operaba sobre una paradoja: formulaba un lenguaje claro, sin la intervención valorativa de un narrador, sin psicologismos, con descripciones objetivas y fenomenológicas, y que, no obstante esa aparente superficialidad, producía un efecto de sentido múltiple y ambiguo. Sólo algunos años antes, Roland Barthes refiriéndose a Robbe- Grillet, había escrito que la "literatura objetiva", contra del modo realista clásico, "le devolvía su delgadez esencial al objeto" (2003: 40), sin querer construir sobre éste significación, ya que él "carece de coartada, espesor y profundidad" (2003: 38), haciendo énfasis, en la materialidad significante y en la circulación abierta del sentido. En el artículo de Marcha, Jitrik encontraba que había un importante antecedente sudamericano: Sin embargo Juan vivia de Alberto Vanasco. ${ }^{5}$ En esta novela "objetivista avant la lettre" publicada en 1947, compuesta por acciones en tiempo futuro, la narración se dispersa en conjeturas, los episodios se desperdigan bajo la condición de hipótesis. Vanasco se acerca a la realidad (sobre la que lanza una y otra vez teorías) no como una materia aprehensible por el lenguaje sino como la multiplicidad de los posibles, un plano que, en el acto de la captación, huye hacia las potencialidades de la ficción. El lenguaje ha renunciado a representar el mundo y, en cambio, se acerca una y otra vez hacia una instancia imprecisa y plural sometida a la contingencia. En esta lectura, como es visible, Jitrik sigue pensando las condiciones del vínculo literatura/realidad en una deriva blanchotiana.

En el cierre de los años cincuenta, Jitrik detecta entonces una fascinación de la literatura de su tiempo por la "realidad". Pero en ese atractivo el crítico solamente encuentra diferencias concurrentes; tanto es así que la "realidad" se extiende hacia lo incierto, lo ambiguo, lo inefable, a la ambigüedad irreducible del mundo, a la "realidad", finalmente, como pura hipótesis. Este recorrido parece señalar, como corolario, la necesidad de una revisión de ese objeto tan teorizado y recurrente, la "realidad", a partir de lo que la misma literatura de ese tiempo estaba poniendo de manifiesto.

\section{Portantiero: del "compromiso" a la tradición de la literatura de izquierda}

Realismo y realidad en la narrativa argentina, el primer libro de Juan Carlos Portantiero, parecía la contracara metodológica del ensayo de Jitrik. Se trata de un estudio sistematizado sobre el realismo en la tradición marxista y sobre la trayectoria histórica de este concepto en la literatura argentina. Ya el mismo título señala un enfoque ambicioso y un señalamiento analítico, bien diferente del corte sincrónico y ecléctico de La nueva promoción. La revolución instalada en América Latina desde 1959 parece, asimismo, poner distancia entre una y otra perspectiva. Ese acontecimiento, "el hecho del socialismo triunfante como posibilidad humana de convivencia entre los hombres" (1961: 16) revitalizaba las expectativas sobre una nueva sociedad y, con ello, la creación de cultura ligada a un modo nuevo de sentir y de ver la realidad.

El objetivo general de Portantiero es intervenir en el debate sobre la narrativa y la crítica ligada al ideario del engagement; esto es, encarar la discusión sobre el avance

5 Es necesario tener en cuenta, respecto de este antecedente que señala Jitrik, que una buena parte de la narrativa de Antonio Di Benedetto contemporánea de La nueva promoción tiene una impronta claramente objetivista, como es visible en Grot/ Cuentos claros (1957), El cariño de los tontos (1961) y sobre todo los dos relatos de Declinación y ángel (1958). 
del imperativo de la "realidad" impulsado por el influjo sartreano y contornista que se había producido en la década anterior, para, desde allí, pensar un realismo contiguo a las prácticas y los debates de la izquierda. Como lo señala María Teresa Gramuglio, para Portantiero sólo el marxismo ofrecía un camino correcto para comprender el sentido de la realidad y no "otras soluciones intelectuales atrapadas en la "conciencia pequeño burguesa de la realidad, como la teoría del compromiso sartreano con su correlato político local, el frondicismo, en el que se habían enrolado los miembros de Contorno" (2012: 145). Desde este punto de vista, el texto de Portantiero tenía como fin arrebatar los conceptos de "realismo" y de "realidad" como bastiones de un sector intelectual (asociado al gobierno de entonces) y en cambio potenciarlos como núcleos de la disputa político-cultural que se había abierto en el continente.

La primera mitad del libro está dedicada a dar forma a una teoría actualizada del realismo marxista. Portantiero abunda en categorías y referencias de esta tradición teórica (Lenin, Engels, Marx, Lefevre, Mariátegui y Agosti), si bien las tesis del texto se orientan hacia una estética heterodoxa de corte gramsciano. La advertencia sobre la autonomía relativa de las superestructuras, la impugnación de la "literatura de tesis" y el rechazo de "dogmas escolásticos, inmutables e impávidos" (1961:7) apuntan hacia esta dirección. Aun así, el trazado conceptual es deudor de las categorías sobre realismo planteadas por György Lukács: realidad objetiva, reflejo, síntesis, totalidad, tipo, unidad de forma y de contenido. Cierta distancia con el teórico húngaro (su figura estaba todavía ligada al régimen estalinista) pone de manifiesto diferencias conceptuales (idealismo, mecanicismo, rechazo hacia la modernidad y la vanguardia), a la vez que sienta una posición disidente, esa misma que, apenas dos años después de la publicación de Realismo y realidad, llevaría a Portantiero junto con otros "jóvenes gramscianos" (Aricó, Schmucler, Del Barco, Torre, Delich) al proyecto intelectual de Pasado y presente (Tarcus, 1999).

Portantiero, recogiendo y aggiornando la tradición teórica del marxismo, sostiene que es necesario considerar al realismo como método y como tendencia histórica. La primera dimensión supone la cualidad aprehensible del mundo por medio del lenguaje, el que, a partir del trabajo del artista, puede ser captado de manera total y sintética. Este enfoque rechaza la idea de la mímesis; la copia es propia de una literatura que no es capaz de apresar la profundidad de las estructuras de la realidad y, por el contrario, permanece en la inmediatez. La literatura realista, antes que un pretendido reflejo superficial, es un modo de conocimiento que requiere de operaciones de apropiación, selección y tipificación. ${ }^{6}$ Esta perspectiva, además de los aportes de Lukács, parecía remitir al "realismo dinámico" de Héctor P. Agosti (1955). Para este teórico, el realismo, que jamás podía estancarse en la mera copia de la realidad, sólo era posible a partir de la mediación o traducción sensible y cognoscitiva del artista, quien podía reunir mundo y conciencia en su obra.

Ahora bien, en tanto "tendencia histórica", Portantiero entendía que la posibilidad de un realismo marxista (y aquí quería distanciarse el realismo socialista soviético) era una corriente privilegiada, sí, pero siempre en el marco de la problemática cultural de su tiempo y en diálogo con la producción artística de un momento determinado. El realismo no es, entonces, una poética prescriptiva, ni un gesto excluyente ni un modelo inamovible, sino "el arte de una concepción del mundo que coincide con la

6 En la operación de captación genuina de la realidad -y de acuerdo con la autonomía relativa de la literatura-se pone en juego una relación proporcional y congruente entre forma y contenido. El desequilibrio entre ambos deriva en un leguaje decadente o en una literatura de tesis. Es imprescindible, así, unidad de los contenidos y de la forma alojada en una percepción sintética. Apunta Portantiero al respecto: “Una vez transformado en producto artístico, esa totalidad no puede descomponerse en elementos simples, porque los contenidos serán ya forma; es decir, que determinado momento de la vida en la apreciación intelectual y sentimental de un artista, se habrá convertido en forma de conciencia y en expresión de ella" (1961: 49). 
objetividad de lo real" (1961:61). Se trata, en cambio, de un modo singular de politizar el arte, de introducir en el centro de la producción artística el concepto de realidad, de inscribir su condición necesaria y de, a la vez, colocarlo como el eje de las disputas político-culturales.

Uno de los puntos centrales desde el que Portantiero desarrolla sus argumentos es la relación entre el "intelectual" (y no el "escritor" de acuerdo con su figura integral en una coyuntura de transformaciones) y el "pueblo-nación". En este sentido, había que considerar la presencia insoslayable de la "realidad" en contigüidad con "el nexo comunitario entre el artista y la sociedad" (1961: 15). Para esto, los "intelectuales" debían deshacerse de hábitos individualistas y de modos de pensamiento distorsivos de la burguesía que impedían la percepción de los problemas sociales reales y de las prácticas consecuentes. Entre esos hábitos se encontraba el mito de la autonomía absoluta, la independencia del intelectual respecto de la sociedad, herencias del "romanticismo restaurador" y del "decadentismo" (y no de la vanguardia, que sí buscaba la fusión del arte con la vida).

La fractura entre el escritor, la obra y la sociedad es uno de los aspectos nucleares a través de los cuales Portantiero ataca la literatura "comprometida" y su modo de erigir la "realidad". El derrotero declinante de la burguesía frente a la emergencia de los movimientos sociales obligaron a los escritores de las capas medias a reconocer la condición "situada" de la literatura, el "compromiso" necesario, la consecuente toma de partido. Con este gesto, la literatura "comprometida" formulaba relaciones abstractas, estáticas y puramente negativas con el mundo, que a menudo derivaban en meras consideraciones morales. El escritor engagé, incapaz de escapar a las contradicciones que le plantea la "dialéctica de la lucha de clases" (1961: 30), no puede renunciar a su lugar individual, meramente denuncialista, ni puede abdicar a la "autonomía de los intelectuales" frente a los desafíos que exige la revolución. Por esto, el "compromiso", aunque se dijera crítico, significaba el fracaso de la relación entre intelectual y el "pueblo-nación" porque era una tentativa cuyo vínculo auténtico con la realidad estaba obstruido. Escribía Portantiero:

El engagement ha alentado la ambigüedad de las capas medias tocadas por la crisis general del sistema, que se resisten a adherir a él, pero que simultáneamente no quieren abdicar de la pretendida 'autonomía de los intelectuales' frente a las formas organizadas de la praxis organizada. (1961:31)

En el caso específico de la Argentina, el peronismo jugó una carta fundamental. La organización masiva de los trabajadores, la instalación del discurso de la lucha de clases y la intervención creciente del Estado movilizó y alteró a la sociedad. Esta irrupción, para Portantiero "populista y reaccionaria" (1961: 73), se convirtió en un factor "de desnudez" (74) que arrinconó el pensamiento y el arte. No había producción artística a partir de 1945, que pudiera escaparse del debate que había planteado el peronismo. En este sentido, el peronismo era el factor de "realidad"-cuando no de trauma, como sucede en las narraciones de Beatriz Guido- frente al cual habían reaccionado los escritores "comprometidos". La actitud negativa de estos intelectuales impugnaba la tradición liberal y, a la vez, los dictados del Estado peronista, pero recogía sus ejes de su debate, que consideraba válidos. Sin embargo, ninguno de ellos rompía su lugar de clase y reformulaba su lazo con la transformación social; su posición crítica, en todo caso, permanecía en términos de pesadumbre o de denuncia.

Bajo estos criterios, Realismo y realidad estudiaba a dos figuras que entendía ejemplares de la "novelística comprometida": David Viñas y Beatriz Guido (ambos habían sido también, recuérdese, parte del grupo analizado en La nueva promoción). Las novelas de Guido redundaban sobre del impacto del peronismo sobre la cultura y la sociedad, 
efecto condensado en las desintegraciones familiares (Zangrandi, 2016). El contacto con la realidad, apuntaba Portantiero, era progresivo; los recorridos psicologistas y domésticos de La casa del ángel y La caída quedaban en un segundo plano en Fin de fiesta, novela en la que construía una visión vasta de la estructura político-social argentina. Sin embargo este derrotero, "base auspiciosa" (1961: 101), estaba restringido por el lugar ideológico inamovible en el que Guido se posicionaba. La toma de conciencia de la crisis social, de este modo, resultaba insuficiente y derivaba en una literatura retórica; el guion de El secuestrador, poblado de escenas brutales, propias del naturalismo, mostraba una mirada prejuiciosa e imaginaria sobre la realidad del barrio marginal. "La novelística de Beatriz Guido" -concluía Portantiero- "se agota en una problemática de raíces éticas, permaneciendo como una crítica moral de la decadencia de las clases altas, pero desde el punto de vista de otro sector ideológico de las mismas clases altas" (1961: 100).

Según Portantiero, la producción de Viñas era paralela. Su narrativa también rodeaba la toma de conciencia de una realidad que había develado el peronismo. El impacto de este movimiento político, no obstante, estaba polarizado; se encontraba, por un lado, encarnado en los valores de lo duro, lo concreto, lo cruel, lo sólido (visible muy notablemente en Los años despiadados y en El jefe), pero a la vez el peronismo era lo absurdo, lo disparatado y lo inverosímil -una figuración muy cercana a las retóricas antiperonistas de Borges, de Ghioldi y de Victoria Ocampo, por ejemplo-. Esta imaginación escindida ponía de manifiesto la perplejidad, propia de los sectores "progresistas" (Portantiero, 1961: 95), frente a lo que había significado el peronismo: su irrupción no podía ser desentrañada profundamente y era percibida solo a partir de impresiones inmediatas y desvinculadas. La simple toma de conciencia era insuficiente para captar la realidad, mucho menos para la integración del intelectual con el "pueblo-nación"; muy por el contrario, esta posición de compromiso daba cuenta de "un deseo inconsciente de no romper radicalmente las vallas de la cosmovisión burguesa" (1961: 103). Aun así, Portantiero coincidía con Jitrik en que el acercamiento más logrado de Viñas a la realidad estaba en Los dueños de la tierra. En ella (tal vez por su escenario más lejano en el tiempo) había una percepción auténtica de la totalidad de una problemática política y social, había tipos, había una captación sintética. Viñas daba un paso propicio desde una literatura de compromiso hacia una "verdadera conciencia de lo real" (1961: 96).

Para poder construir un lazo genuino entre literatura y realidad, apuntaba Portantiero, había que dejar a un lado la toma de postura y, en cambio, revisar la tradición literaria de la izquierda, desde los antecedentes de Cambaceres y Podestá a Sánchez y Payró; de Boedo a Varela, Pla y Verbitsky. Aunque perjudicada por el naturalismo, el costumbrismo y un tratamiento a menudo retórico del mundo, en esta literatura había un proyecto de integración entre escritores y la sociedad. En particular, la producción de Boedo, que había heredado las carencias de esta tradición, podría haber sido capital si hubiera sido capaz de incorporar las innovaciones formales que habían logrado otros núcleos de vanguardia de los años veinte. Portantiero estaba apuntando hacia Contorno, que, en sus recorridos y exámenes de la literatura argentina (esto es, en su construcción de un nuevo canon), no había encontrado en Boedo un modelo para la literatura de izquierda. Si se buscaba una narrativa enlazada con la realidad había que dar un paso dialéctico que formulara una literatura honda y definidamente conectada con el mundo, una escritura crítica y creativa, intelectuales que reinventaran su lugar y su praxis en vistas a un horizonte socialista. Concluía entonces Portantiero que

sólo a través del realismo, la izquierda -desde Boedo hasta los "comprometidos"superará el desgarramiento de su separación del pueblo. Porque el realismo obliga al intelectual a una elección; lo libra de la ambigüedad, lo inserta en la historia. Fuera de él, en esta Argentina en la que han caducado las soluciones intermedias, solo queda el conformismo o la soledad. (1961: 129) 
En una instancia de inflexión política y cultural, los ensayos de Jitrik y Portantiero anudan los debates alrededor al imperativo realista que domina los años cincuenta y sesenta. Claudia Gilman ha señalado, justamente, el modo en que el realismo se asentó en el campo literario latinoamericano en tanto "mot d'ordre y contraseña crítica" (2012: 320) bajo una forma singular: una poética que combinaba un lenguaje capaz de aprehender el mundo en sus estructuras profundas, la toma de posición y la búsqueda de formas modernas, a medio camino, y según las palabras de Carlos Fuentes que Gilman recupera, entre Honoré de Balzac y Michel Butor (2012: 318). En el debate que enfrentan las perspectivas de Realismo y realidad y La nueva promoción, se articulan los dilemas de la literatura posperonista y los que se abrirían en los sesenta: la novela como forma privilegiada de la producción, la búsqueda de un lenguaje que da cuenta de la multiplicidad de la realidad, el lazo necesario entre literatura y realidad, la oscilación de la figura del escritor entre la responsabilidad y la acción.

La orientación política de los análisis pone de manifiesto, asimismo, la estructuración posible de un canon y, en este sentido, de determinadas exclusiones. Puede observarse, de acuerdo con esto, la coincidencia sobre algunas figuras y líneas de aquel presente. En un debate sobre el realismo en aquel pasaje de décadas hay una figura que hoy está notablemente ausente: Rodolfo Walsh, quien en 1957 había publicado Operación masacre. Este libro renovó la relación de la literatura con la realidad política, expuso una modalidad novedosa de construir la narración y se reformuló la figura del escritor. Walsh no figura en los ensayos de Jitrik y de Portantiero, aun cuando ambos críticos toman como objetos de estudio novelas muy recientes. La filiación nacionalista de Walsh (la campaña periodística de Operación masacre se publicó en las revistas Mayoría y Azul y blanco) obturó la posibilidad de que fuera por entonces leído, tanto menos de ser incorporado a un canon que quería estrechar los lazos de la literatura con la realidad.

Los enfoques metodológicos de los textos de Noé Jitrik y de Juan Carlos Portantiero, finalmente, señalan dos caminos, dos modos de labor sobre la praxis crítica. La sistematización y el armado teórico sólido de Realismo y realidad, su trazado lúcido sobre la narrativa argentina, coloca, no obstante, el aparato crítico por encima de la producción literaria. Tanto es así que, aunque rechaza toda prescriptiva, ninguna figura, ninguna obra termina ajustándose a las categorías analíticas y, por ende, Portantiero debe cerrar el ensayo con indicaciones deónticas. Sin este apuntalamiento teórico, sin, incluso, la construcción de una tradición para el corpus que propone, Jitrik explora el concepto de "realidad" a partir de la lectura de un grupo de novelas recientes. De este análisis no obtiene sino distintos acercamientos al objeto "realidad". La nueva promoción, ecléctico y parado sobre las incertidumbres del presente, encuentra que un lazo tan fundamental y siempre actual como el que liga la realidad y la literatura solo puede ser pensado en tanto se transforma, se reinventa y se multiplica. 


\section{Q Bibliografía}

» Barthes, R. (2003). Ensayos críticos. Buenos Aires: Seix Barral.

»Blanchot, M. (1981). De Kafka a Kafka. México, Fondo de Cultura Económica.

»Cernadas, J. (1997). “Notas sobre la desintegración del consenso antiperonista en el campo intelectual: Sur, 1955-1960". En Oteiza, E. (Coord.), Cultura y política en los años “6o (pp. 133-149). Buenos Aires: Instituto de Investigaciones "Gino Germani”, Facultad de Ciencias Sociales, Universidad Nacional de Rosario.

" Confirmado (1965, 30 de setiembre). Manuel Mujica Lainez. Respuestas de un exquisito. Confirmado, $n^{\circ} 22$, pp. $42-43$.

" Gilman, C. (2012). Entre la pluma y el fusil. Debates y dilemas del escritor revolucionario en América Latina. Buenos Aires: Siglo XXI.

» Gramuglio, M. T. (2011). “Prólogo”. En Portantiero, J. C., Realismo y realidad en la narrativa argentina (pp. 9-25). Buenos Aires: Eudeba.

»Gramuglio, M. T. (2012). Política y debates literarios en el umbral de los años sesenta. (A propósito de la reedición de Realismo y realidad en la narrativa argentina). CELEHIS. Revista del Centro de Letras Hispanoamericanas, $\mathrm{n}^{\circ} 23$, pp. 141155, Universidad Nacional de Mar del Plata.

» Gramuglio, M. T. (2014). "El realismo y sus destiempos en la literatura argentina”. En Gramuglio, M. T. y Jitrik, N. (Dir.), Historia crítica de la literatura argentina, vol. 6: El imperio realista (pp. 15-38). Buenos Aires: Emecé.

» Jitrik, N. (1959). Seis novelistas argentinos de la nueva promoción. Mendoza: Cuadernos de Versión.

» Jitrik, N. (1960, 16 de setiembre). Un precursor del nuevo realismo. Marcha, 1026, 21.

»Lukács, G. (1966). Problemas del realismo. México: Fondo de Cultura Económica.

"Masotta, O. (2008) [1965]. Sexo y traición en Roberto Arlt. Buenos Aires: Eterna Cadencia.

»Portantiero, J. C. (1961). Realismo y realidad en la narrativa argentina. Buenos Aires: Procyon.

» Sartre, J. P. (2003) [1950]. ¿Qué es la literatura? Buenos Aires: Losada.

» Tarcus, H. (1999). “El corpus marxista”. En Cella, S. y Jitrik, N. (Dir.), Historia crítica de la literatura argentina, vol. 10: La irrupción de la crítica (pp. 465-500). Buenos Aires: Emecé.

» Terán, O. (1991). Nuestros años sesentas. La formación de la nueva izquierda intelectual en Argentina 1956-1966. Buenos Aires: Puntosur.

»Vanasco, A. (1967) [1947]. Sin embargo Juan vivía. Buenos Aires: Sudamericana.

»Zangrandi, M. (2016). Familias póstumas. Literatura argentina, fuego, peronismo. Buenos Aires: Godot. 